1 Department of Dental Clinic, Federal University of Rio de Janeiro. Rio de Janeiro, RJ, Brazil.

2 Piracicaba Dental School, State University of Campinas, Piracicaba, SP, Brazil

${ }^{3}$ Federal University of Rio de Janeiro, Metallurgical and Materials Engineering, Rio de Janeiro, RJ, Brazil.
Corresponding author: Carolina Oliveira de Lima Rua Rogério Karp 310 - Recreio dos Bandeirantes - Rio de Janeiro, Brazil

Zip: $22795-216$

E-mail:c.oliveiradelima@yahoo.com.br

Received: May 10, 2018

Accepted: November 09, 2018

\section{Effect of a sonic device on bonding of fiberglass posts to root canals}

\author{
Marina de Almeida Salim", Thais Mageste Duque², \\ Heloisa Carla Dell Santo Gusman ${ }^{1}$, Carolina Oliveira \\ de Lima', Brenda Paula Figueiredo de Almeida \\ Gomes $^{2}$, Renata Antoun Simão ${ }^{3}$, Maíra do Prado ${ }^{3}$
}

Aim: This study evaluated the effect of a sonic device on the bonding of fiberglass posts cemented with a self-etching adhesive combined with conventional cement or a self-adhesive cement to root dentin. Methods: Forty single-rooted bovine incisors were endodontically prepared using a step-back technique. Gutta-percha and AH Plus sealer were used for root canal filling, combined with a thermoplasticization technique. After 1 week, the post space was prepared and the roots were divided into four groups according to the following factors: adhesive system/resin cement (Ambar/ AllCem Core [FGM] and RelyX U200 [3M]) and application mode (manual or sonic). The posts were cemented and the roots were cut into discs and submitted to push-out bond strength (POBS) test. The failure mode was evaluated using a stereoscope at $25 x$ magnification. The data were analyzed statistically using ANOVA and Tukey's post-hoc test $(\alpha=0.05)$. Results: The sonically activated RelyX U200 group was superior to the other groups. RelyX U200 manually applicated showed similar results to those of sonically activated Âmbar/AllCem. These three groups outperformed the Âmbar/AllCem manually applicated group. Adhesive failure between dentin and resin cement was the most predominant pattern. Conclusion: Sonic application of self-etching adhesive and self-adhesive cement improved the POBS of fiber posts to the root canal.

Keywords: Dental pulp cavity. Dental pins. Dental cements. Dental bonding. Dental stress analysis. 


\section{Introduction}

It is well established that coronal infiltration is a major cause of failure in endodontics ${ }^{1-3}$. Thus, an impervious seal in the coronal area is vital for a successful prognosis of an endodontically treated tooth ${ }^{4}$. Indirect restorations are frequently required after endodontic treatment due to the extensive loss of tooth structure as a result of carious lesions and previous restorations and/or fractures. These restorations are commonly associated with cast-metal or fiberglass posts ${ }^{5}$.

Fiberglass posts are widely used and accepted for restoration of endodontically treated teeth due to their good esthetic appearance, with no risk of gingival discoloration or alteration of the root surface by corrosive products, especially in the anterior region ${ }^{6}$. Furthermore, they have a high flexural strength and an elastic modulus similar to that of dentin, thus minimizing the transmission of stresses to the root walls and decreasing the possibility of root fractures ${ }^{5-8}$.

Fiberglass posts can be cemented using different techniques such as conventional adhesive (etch-and-rinse) associated with conventional cement, self-etching adhesive associated with conventional cement, and self-adhesive cement. In respect to self-etching systems, they do not require the use of acids or chelating agents for smear layer removal. Self-adhesive cement requires no pre-treatment of the tooth surface. This is a simplified and time-saving cementation procedure with a bonding mechanism based on micromechanical retention and chemical ${ }^{5}$.

Clinical studies have shown that loss of retention is the major failure mode of fiber posts luted to root canals $s^{9-11}$. This can occur because the light from the curing unit fails to reach the most apical regions or because of the incompatibility between acid adhesives and self-/dual-polymerized composites. In addition, problems may result from high polymerization contraction stresses, poor moisture control, and peculiar characteristics of the root dentin substrate $\mathrm{e}^{11-17}$.

Several strategies have been suggested to improve the performance of adhesive systems; however, they usually add more bonding steps or time to the clinical procedure ${ }^{11,18}$. Cuadros-Sanchez et al. ${ }^{11}$ (2014) observed that the application of conventional adhesive using a sonic device was a feasible tool to increase fiber post bonding to root canals.

The aim of the present study was to evaluate the effect of a sonic device on the bonding of fiberglass posts cemented with a self-etching adhesive combined with conventional cement (Ambar Universal/ AllCem Core) or a self-adhesive cement (RelyX U200) to root dentin.

\section{Materials and Methods}

\section{Specimen preparation}

Forty single-rooted bovine incisors were selected for this study. The inclusion criteria were absence of root resorption, fracture and cracks - visualized with mesiodistal and bucallingual radiographs. The round internal anatomy and diameter were equivalent to that of Gates-Glidden (GG) drills \# 3 to \#5 in the cervical and middle third.

The crowns were sectioned below the cementoenamel junction using a double-sided diamond disc (KG Sorensen, Barueri, SP, Brazil) to obtain 14-mm-long roots. 
Afterwards, the pulp tissue was removed using a \#30 Hedstroem (Dentsply Maillefer, Ballaigues, Switzerland) endodontic file, to better removal of bovine pulp tissue due to its high cutting capacity, but it was not used for patency.

The root canal was explored with endodontic files \#10 and \#15 (Dentsply Maillefer, Ballaigues, Switzerland). A step-back technique was used to shape the root canals. To prepare the middle-coronal third, GG 5 (Dentsply Maillefer, Ballaigues, Switzerland) was used at $5 \mathrm{~mm}$ and GG4 at $8 \mathrm{~mm}$. The K3 (SybronEndo, Orange, CA, USA) sequence was used for apical preparation: $15 / .06,20 / .06,25 / .06,30 / .06,35 / .06$ and $40 / .06$. The canals were irrigated with $1 \mathrm{~mL}$ of $5.25 \%$ sodium hypochlorite (Milfórmulas, Rio de Janeiro, RJ, Brazil) between files. $1 \mathrm{~mL}$ of $17 \%$ EDTA (Biodinâmica, Ibiporã, PR, Brazil) was used during 3 minutes, followed by $5 \mathrm{~mL}$ of saline solution, to remove the smear layer. The canals were dried with medium-sized absorbent paper cones (EndoPoints $($, Manacapuru, AM, Brazil). They were then filled with medium-sized gutta-percha cones (Odous de Deus, Belo Horizonte, MG, Brazil) and AH Plus $^{\text {TM }}$ sealer (Dentsply, Petropolis, RJ, Brazil). The gutta percha and paper cones were cut at size 40.The canals were filled using a thermoplasticization technique. All the teeth were radiographed to assess the quality of the filling and verify whether the three-dimensional filling had any voids. The specimens were stored at $37^{\circ} \mathrm{C}$ and $100 \%$ humidity for 1 week.

The filling material was then removed with a heat condenser \#3 (Odous de Deus, Belo Horizonte, MG, Brazil) at 10mm. Post space was prepared with Gates Glidden \#5 (Maillefer) at 7mm and a specific bur of the post system (White Post DC@ \# 2, FGM, Joinville, SC, Brazil), with similar dimensions to those of the fiberglass post (height $20 \mathrm{~mm}$, upper and lower diameter $1.8 \mathrm{~mm}$ and $1.05 \mathrm{~mm}$, respectively) was used at $10 \mathrm{~mm}$. After that, the post space was cleaned with $70 \%$ alcohol using a microapplicator (Cavibrush, FGM, Joinville, SC, Brazil), followed by irrigation with $5 \mathrm{~mL}$ of saline solution. The root canals were then dried with paper points (EndoPoints $\otimes$ ) and air jets.

The teeth were randomly divided into four groups ( $n=10)$ (Table 1): adhesive system/ resin cement (Ambar Universal/ AllCem Core and only RelyX U200) and application mode (manual or sonic).

The post was prepared using 37\% phosphoric acid (Condac 37, FGM, Joinville, SC, Brazil) for 30 seconds, washed with distilled water, and dried with air jets. The Âmbar Universal (FGM, Joinville, SC, Brazil) adhesive was applied to the groups cemented with AllCem Core (FGM, Joinville, SC, Brazil) and Single Bond Universal (3M ESPE, St. Paul, MN, USA) was used in the group cemented with RelyX U200 (3M ESPE, St. Paul, MN, USA). The adhesive was applied homogeneously on the fiber post surface using a microapplicator (Cavibrush, FGM) and polymerized for 20 seconds (Radii Cal;SDI, Baywater, Australia) at $1.200 \mathrm{~mW} / \mathrm{cm}^{2}$.

Groups 1 and 3 were cemented with AllCem Core/Âmbar Universal. In Group 1, Âmbar Universal was applied to the dentinal surface for 10 seconds with a microapplicator, followed by a second application for 10 seconds, and the excess adhesive was removed with paper

Table 1. Experimental groups.

\begin{tabular}{lcc}
\hline Groups & Adhesive system/ resin cement & Application mode \\
\hline 1 & Ambar Universal/ AllCem Core & Manual application \\
\hline 2 & RelyX U200 & Manual application \\
\hline 3 & Ambar Universal/ AllCem Core & Sonic application \\
\hline 4 & RelyX U200 & Sonic application \\
\hline
\end{tabular}


points (EndoPoints $®$ ). Thereafter, it was polymerized for 20 seconds. In Group 3, Âmbar Universal was applied with a specific sonic system microapplicator (Smart Sonic, FGM, Joinville, SC, Brazil) at middle frequency $170 \mathrm{~Hz}$, for 20 seconds and polymerized for 20 seconds. AllCem Core was then inserted with a Centrix syringe (DFL, Rio de Janeiro, RJ, Brazil).

Group 2 and 4 were cemented with RelyX U200. In Group 2, the cement was inserted with a Centrix syringe (DFL). In Group 4, after cement insertion, sonic agitation was performed for 20 seconds using the tip of the sonic device, ate $170 \mathrm{~Hz}$.

The posts (DC \#2, FGM) were placed with tweezers and digital pressure after cement inserted and after 5 minutes, each face was polymerized for 40 seconds. The samples were stored at $37^{\circ} \mathrm{C}$ and $100 \%$ humidity for 1 week.

\section{Push-out test}

Each root was horizontally sectioned with a low-speed, water-cooled diamond saw (Isomet 2000; Buehler, Lake Bluff, IL) to produce two slices of approximately $1 \mathrm{~mm}$ of each root region (i.e., apical, middle, and coronal). The first (coronal) and last (apical) slices were discarded. Six slices from each root canal were evaluated.

The push-out test was performed using a cylindrical stainless steel plunger $(1.2 \mathrm{~mm}$ in diameter), with a load at $0.5 \mathrm{~mm} / \mathrm{min}$ from the apical to the coronal direction until the post segment was dislodged from the root section. The push-out bond strength was measured with a universal testing machine (EMIC DL 2000; São José dos Pinhais, PR, Brazil). To express the bond strength in megapascals (MPa), the load at failure, recorded in newtons $(\mathrm{N})$, was divided by the area $\left(\mathrm{mm}^{2}\right)$ of the post-dentin interface. To calculate the bonding area, the formula $p(R+r)\left[\left(h^{2}+(R-r)^{2}\right]^{0.5}\right.$ was used, where $R$ represents the coronal root canal radius, $r$ is the apical root canal radius, and $h$ is the thickness of the slice. The thickness of each slice was measured using a digital caliper (Starrett, Itu, SP, Brazil) and the total bonding area for each root canal segment was measured under 25x magnification with a stereoscope (Carl Zeiss) and ImageLab 2.3 software (University of Campinas, Piracicaba, SP, Brazil).

All fractured specimens were observed under a stereoscope (Carl Zeiss) at 25x magnification to determine the failure mode. The failure mode was classified into five types: (i) Adhesive between cement and dentin: fracture occurs predominantly at the cement/dentin interface; (ii) Adhesive dentin/cement/post: the fracture occurs without predominance of an interface; (iii) Mixed cohesive dentin: some fracture occurs within dentin; (iv) Mixed cohesive post: fracture occurs at the post; (v) Mixed cohesive post/dentin: fracture occurs at the post and dentin. The assessment was performed by a single experienced evaluator.

\section{Statistical analysis}

The Kolmogorov-Smirnov and Levene's tests were used to evaluate normality and heteroskedasticity. The data were then analyzed statistically using ANOVA and Tukey's post-hoc test for comparisons $(\alpha=0.05)$. IBM SPSS version 15.0 and the R software version 3.2.3 were used.

\section{Results}

Mean and standard deviation values of the push-out bond strengths are reported in Table 2. When the groups were evaluated independent of the third (all thirds), the 
sonically activated RelyX U200 was superior to the other groups. RelyX U200 manually applicate and sonically activated Âmbar/AllCem results were similar. These three groups were superior to the manually applicate Âmbar/AllCem group.

Regarding cements, RelyX U200 showed superior results, i.e., RelyX U200 was superior to Âmbar/AllCem and the sonically activated RelyX U200 was superior to the sonic activated Âmbar/AllCem.

The sonic device increased the bond strength of both cements.

Similar values were observed for the push-out values of the thirds. In all thirds, Âmbar/ AllCem showed lower bond strength.

As shown in Figure 1, the most predominant failure pattern was type I, i.e., adhesive between dentin and resin cement.

Table 2. Mean and standard deviation values (MPa) of bond strength.

\begin{tabular}{lcccc}
\hline & Âmbar/AllCem & RelyX U200 & Âmbar/AllCem Sonic & RelyX U200 Sonic \\
\hline Cervical & $6.47 \pm 2.69^{\mathrm{aB}}$ & $9.58 \pm 3.46^{\mathrm{aA}}$ & $10.04 \pm 3.84^{\mathrm{aA}}$ & $12.10 \pm 3.39^{\mathrm{aA}}$ \\
\hline Middle & $6.98 \pm 3.22^{\mathrm{aB}}$ & $8.98 \pm 3.41^{\mathrm{aA}}$ & $9.88 \pm 3.74^{\mathrm{aA}}$ & $10.10 \pm 2.76^{\mathrm{aA}}$ \\
\hline Apical & $5.17 \pm 3.02^{\mathrm{aC}}$ & $9.24 \pm 2.21^{\mathrm{aAB}}$ & $8.10 \pm 3.36^{\mathrm{aBC}}$ & $11.96 \pm 4.69^{\mathrm{aA}}$ \\
\hline Total & $6.28 \pm 3.02^{\mathrm{C}}$ & $9.27 \pm 3.06^{\mathrm{B}}$ & $9.30 \pm 3.69^{\mathrm{B}}$ & $11.36 \pm 3.69^{\mathrm{A}}$ \\
\hline
\end{tabular}

Different superscript capital letters ${ }^{(A-C)}$ indicate statistically significant differences by row. Similar superscript lowercase letters ${ }^{(\mathrm{a})}$ indicated no statistically significant differences by column (ANOVA and Tukey tests, $\mathrm{p}<0.05)$.

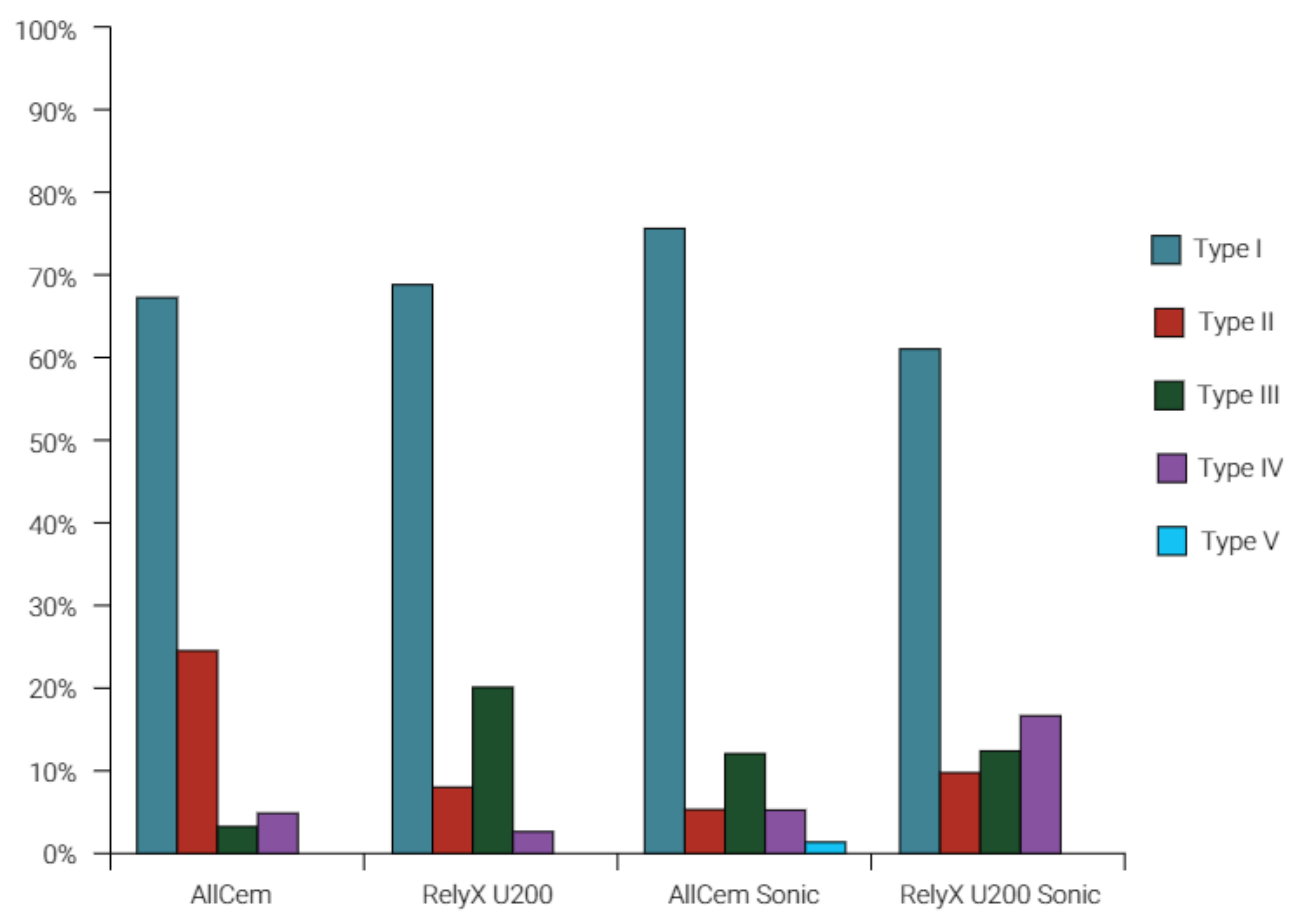

Figure 1. Failure patterns. 


\section{Discussion}

An effective and durable bonding of fiber posts to cement and cement to dentin is essential for the longevity of restorations and for endodontic prognosis ${ }^{6}$. Different strategies have been proposed to improve the adhesion of fiber posts to dentin. However, these strategies are associated with increasing steps during the cementation process, such as resin cement pre-heating ${ }^{19}$, dentin pretreatments ${ }^{20-22}$ and different surface treatments of fiber-reinforced posts ${ }^{23}$.

Cuadros-Sanchez et al. ${ }^{11}$ (2014) evaluated the sonic application of a conventional adhesive system and observed that it improved the adhesion of fiber post to dentin in addition to increasing the penetration of the adhesive. In view of these findings, the present study evaluated the effect of a sonic device on the bonding of fiberglass posts cemented with a self-etching adhesive combined with conventional cement (Âmbar/AllCem) or self-adhesive cement (RelyX U200) to root dentin.

The present study verified that the sonically activated RelyX U200 was superior to the other groups, while the Âmbar/AllCem group yielded the worst results. RelyXU200, a self-adhesive cement, outperformed AllCem Core plus the self-etching adhesive. The simplified self-adhesive resin cement approach allows low shrinkage due to its viscoelastic properties, leading to a better intimate contact of the resin cement with the root canal walls and higher frictional resistance ${ }^{24}$. According to Radovic et al. ${ }^{25}$ (2008), the setting reaction of self-adhesive cements results in extensive cross-linking of monomers and in the creation of high molecular weight polymers. To neutralize the acid system, the $\mathrm{pH}$ increases from 1 to 6 because phosphoric acids react with alkaline fillers and with tooth apatite. In this process, water is formed, which contributes to the cement's hydrophilicity, leading to a better adaptation to root canal walls and moisture tolerance. In addition, the use of sonic device increased the bond strength of both cements, similar to other studies ${ }^{11,26}$.

The negative results of AllCem Core associated with Âmbar Universal autoconditioning bonding can be due to a possible chemical incompatibility between the low-pH adhesive system and the resinous material24. Amaral et al. ${ }^{24}$ (2009) found superior bond strength results for RelyX Unicem, a self-adhesive cement, precursor of RelyX U200, in comparison with the self-etching adhesive Panavia F system, using the pull-out test. However, Pereira et al. ${ }^{27}$ (2014) found similar performance when comparing self-adhesive cements (RelyX Unicem and BisCem) with the self-etching adhesive (Panavia F system) using the same test.

The use of a sonic device favored the bond strength of both cements. An explanation for the better performance of the sonically activated groups is that, under sonic vibration, the imparted energy is transmitted to the fluid bonding agent within the root canal. The agitated fluid can reach areas not accessible by the sonic tip. In addition, the high-speed vibration of the sonic tip creates pressure waves and shear forces in the adhesive and also generates microscopic bubbles that are forcefully pushed against the dentin surfaces. In combination, this fluid dynamics are able to increase the inward diffusion of monomers while aiding in the outward evaporation of solvents, which reduces the smear layer and consequently reduces the nanoleakage, thus increasing bond strength ${ }^{11-28}$. Our findings are in accordance 
with Cuadros-Sanchez et al. ${ }^{11}$ (2014) and Mena-Serrano et al. ${ }^{28}$ (2014), who found improvement in bond strength when a sonic device $(170 \mathrm{~Hz}$ frequency) was used. However, Mushashe et al. ${ }^{29}$ (2017) verified that the use of a sonic device $(241 \mathrm{~Hz}$ frequency) did not improved the bond strength. The differences in the results obtained can be ascribed to oscillatory frequencies.

In the present study, no difference was found in bond strength between the thirds, which is partially in accordance with Saraiva et al. ${ }^{22}$ (2013). These similar results may be associated with the homogeneous cleaning performed in dentin, which allowed complete penetration of the resin into the dentin. Both cements used are dual-cured and contain components that provide rapid light polymerization in those areas where the curing light penetrates effectively and a slower chemical polymerization in those areas where the light is not effective ${ }^{18}$. However, these findings are at odds with Cuadros-Sanchez et al. ${ }^{11}$ (2014), who found lower values for the apical third in the push-out test.

Adhesive failure between cement and dentin was the most common finding, which is in accordance with previous studies 6,11,27. The sonically activated RelyX U200 group exhibited higher bond strength and the most mixed cohesive failure patterns ${ }^{30}$.

Further studies are needed to evaluate long-term laboratory and clinical performance of adhesives/resin cements when different application modes are used.

It may be concluded that sonic application of self-etching adhesive and self-adhesive cement improved the bond strength of fiber posts to the root canal.

\section{Acknowledgments}

We would like to thank FGM and 3M for the donation of the posts and cements.

This research was supported by Coordination for the Improvement of Higher Education Personnel (CAPES).

\section{References}

1. Saunders WP, Saunders EM. Coronal leakage as a cause of failure in root canal-therapy: A review. Endod Dent Traumatol. 1994 Jun; 10(3):105-8.

2. Ray HA, Trope M. Periapical status of endodontically treated teeth in relation to the technical quality of the root filling and the coronal restoration. Int Endod J. 1995Jan;28(1):12-8.

3. Swanson K, Madison S. An evaluation of coronal microleakage in endodontically treated teeth. Part I. Time periods. J Endod. 1987 Feb;13(2):56-9.

4. Tabassum S, Khan FR. Failure of endodontic treatment: the usual suspects. Eur J Dent. 2016 Jan-Mar; 10(1):144-7. doi: 10.4103/1305-7456.175682.

5. Cecchin D, Farina AP, Souza MA, Carlini-Júnior B, Ferraz CC. Effect of root canal sealers on bond strength of fibreglass posts cemented with self-adhesive resin cements. Int Endod J. 2011 Apr;44(4):314-20. doi: 10.1111/j.1365-2591.2010.01831.x.

6. Ferreira R, Prado M, de Jesus Soares A, Zaia AA, de Souza-Filho FJ. Influence of using clinical microscope as auxiliary to perform mechanical cleaning of post space: A bond strength analysis. J Endod. 2015 Aug;41(8):1311-6. doi: 10.1016/j.joen.2015.05.003. 
7. Costa Dantas MC, do Prado M, Costa VS, Gaiotte MG, Simão RA, Bastian FL. Comparison between the effect of plasma and chemical treatments on fiber post surface. J Endod. 2012 Feb;38(2):215-8. doi: 10.1016/j.joen.2011.10.020.

8. Kececi AD, Ureyen Kaya B, Adanir N. Micro push-out bond strengths of four fiber-reinforced composite post systems and 2 luting materials. Oral Surg Oral Med Oral Pathol Oral Radiol Endod. 2008 Jan; 105(1):121-8.

9. Rasimick BJ, Wan J, Musikant BL, Deutsch AS. A review of failure modes in teeth restored with adhesively luted endodontic dowels. J Prosthodont. 2010 Dec;19(8):639-46. doi: 10.1111/j.1532-849X.2010.00647.x.

10. Cagidiaco MC, Goracci C, Garcia-Godoy F, Ferrari M. Clinical studies of fiber posts: a literature review. Int J Prosthodont. 2008 Jul-Aug;21(4):328-36.

11. Cuadros-Sanchez J, Szesz A, Hass V, Patzlaff RT, Reis A, Loguercio AD. Effects of sonic application of adhesive systems on bonding fiber posts to root canals. J Endod. 2014 Aug;40(8):1201-5. doi: 10.1016/j.joen.2013.12.034.

12. Cerruti F, Acquaviva PA, Gagliani M, Ferrari M, Mangani F, Depero LE, et al. Degree of conversion of dual-cure resins light-cured through glass-fiber posts. Am J Dent. 2011 Feb;24(1):8-12.

13. Halvorson RH, Erickson RL, Davidson CL. Energy dependent polymerization of resin-based composite. Dent Mater. 2002 Sep;18(6):463-9.

14. Cheong C, King NM, Pashley DH, Ferrari M, Toledano M, Tay FR. Incompatibility of self-etch adhesives with chemical/dual-cured composites: two-step vs one-step systems. Oper Dent. 2003 Nov-Dec;28(6):747-55.

15. Bouillaguet S, Troesch S, Wataha J, Krejci I, Meyer JM, Pashley DH. Microtensile bond strength between adhesive cements and root canal dentin. Dent Mater. 2003 May;19(3):199-205.

16. Bouillaguet S, Bertossa B, Krejci I, Wataha JC, Tay FR, Pashley DH. Alternative adhesive strategies to optimize bonding to radicular dentin. J Endod. 2007 Oct;33(10):1227-30.

17. Ferrari M, Vichi A, Gradini S. Efficacy of different adhesive techniques on bonding to root canal walls: an SEM investigation. Dent Mater. 2001 Sep;17(5):422-9.

18. Schwartz RS. Adhesive dentistry and endodontics. Part 2: bonding in the root canal system-the promise and the problems: a review. J Endod. 2006 Dec;32(12):1125-34.

19. Oskoee PA, Nooroloyouni A, Azar FP, Oskoee S, Ashraf AP. Effect of resin cement pre-heating on the push out bond strength of fiber post to root canal dentin. J Dent Res Dent Clin Dent Prospects. 2015 Fall;9(4):233-8. doi: 10.15171/joddd.2015.042.

20. Kul E, Yeter KY, Aladag LI, Ayranci LB. Effect of different post space irrigation procedures on the bond strength of a fiber post attached with a self-adhesive resin cement. J Prosthet Dent. 2016 May;115(5):601-5. doi: 10.1016/j.prosdent.2015.10.010.

21. Victorino KR, Kuga MC, Duarte MA, Cavenago BC, Só MVR, Pereira JR. The effects of chlorhexidine and ethanol on push-out bond strength of fiber posts. J Conserv Dent. 2016 Jan-Feb;19(1):96-100. doi: 10.4103/0972-0707.173210.

22. Saraiva LO, Aguiar TR, Costa L, Correr-Sobrinho L, Muniz L, Mathias P. Effect of different adhesion strategies on fiber post cementation: Push-out test and scanning electron microscopy analysis. Contemp Clin Dent. 2013 Oct;4(4):443-7. doi: 10.4103/0976-237X.123022.

23. Arslan H, Ayranci LB, Kurklu D Topcuoglu HS, Barutcigil C. Influence of different surface treatments on push-out bond strengths of fiber-reinforced posts luted with dual-cure resin cement. Niger J Clin Pract. 2016 Mar-Apr;19(2):218-22. doi: 10.4103/1119-3077.175962. 
24. Amaral M, Santini MF, Wandscher V, Amaral R, Valandro LF. An in vitro comparison of different cementation strategies on the pull-out strength of a glass fiber post. Oper Dent. 2009 Jul-Aug;34(4):443-51. doi: 10.2341/08-113.

25. Radovic I, Monticelli F, Goracci C, Vulicevic ZR, Ferrari M. Self-adhesive resin cements: a literature review. J Adhes Dent. 2008 Aug;10(4):251-8.

26. Mena-Serrano A, da Costa TRF, Patzlaff RT, Loguercio AD, Reis A. Effect of sonic application mode on the resin-dentin bond strength and dentin permeability of self-etching systems. J Adhes Dent. 2014 Oct; 16(5):435-40. doi: 10.3290/j.jad.a32810.

27. Pereira JR, da Rosa RA, do Valle AL, Ghizoni JS, Só MV, Shiratori FK. The influence of different cements on the pull-out bond strength of fiber post. J Prosthet Dent. 2014 Jul;112(1):59-63. doi: 10.1016/j.prosdent.2013.10.009.

28. Mena-Serrano A, Garcia EJ, Loguercio AD, Reis A. Effect of sonic application mode on the resindentin bond strength and nanoleakage of simplified self-etch adhesive. Clin Oral Investig. 2014 Apr;18(3):729-36. doi: 10.1007/s00784-013-1019-y.

29. Mushashe AM, Amaral RO, Rezende CE, Baratto Filho F, Cunha LF, Gonzaga CC. Effect of sonic vibrations on bond strength of fiberglass posts bonded to root dentin. Braz Dent $\mathrm{J}$. 2017 Jan-Feb;28(1):30-34. doi: 10.1590/0103-6440201601107.

30. Perdigão J, Gomes G, Augusto V. The effect of dowel space on the bond strengths of fiber posts. J Prosthodont. 2007 May-Jun;16(3):154-64. 